\title{
A Novel Approach for Identification and Characterization of Glycoproteins Using a Hybrid Linear Ion Trap/FT-ICR Mass Spectrometer
}

\author{
Scott M. Peterman and Joseph J. Mulholland \\ Thermo Electron Corporation, Somerset, New Jersey, USA
}

Combining source collision-induced dissociation (CID) and tandem mass spectral acquisition in a pseudo-MS ${ }^{3}$ experiment using a linear ion trap results in a highly selective and sensitive approach to identifying glycopeptide elution from a protein digest. The increased sensitivity is partially attributed to the nonselective nature of source CID, which allows simultaneous activation of all charge states and coeluting glycoforms generating greater ion abundance for the mass-to-charge $(\mathrm{m} / \mathrm{z}) 204$ and/or 366 oxonium ions. Unlike source CID alone, a pseudo$\mathrm{MS}^{3}$ approach adds selectivity while improving sensitivity by eliminating chemical noise during the tandem mass spectral acquisition of the oxonium ions in the linear ion trap. Performing the experiments in the hybrid linear ion trap/Fourier transform-ion cyclotron resonance (FT-ICR) enables subsequent high-resolution/high-mass accuracy full-scan mass spectra (MS) and parallel acquisition of MS/MS in the linear ion trap to be completed in $2 \mathrm{~s}$ directly following the pseudo-MS ${ }^{3}$ scan to collate identification and characterization of glycopeptides in one experimental scan cycle. Analysis of bovine fetuin digest using the combined pseudo-MS ${ }^{3}$, high-resolution MS, and data-dependent MS/MS events resulted in identification of four $\mathrm{N}$-linked and two $\mathrm{O}$-linked glycopeptides without enzymatic cleavage of the sugar moiety or release of the sialic acids before analysis. In addition, over $95 \%$ of the total protein sequence was identified in one analytical run. (J Am Soc Mass Spectrom 2006, 17, 168-179) @ 2006 American Society for Mass Spectrometry

$\mathrm{R}$ ecent developments in biological mass spectrometry have made protein sequencing routine, thereby allowing a deeper research focus on posttranslational modifications (PTMs) at the cellular level. Protein glycosylation is of particular interest since it is the most common protein modification [1-5]. Glycosylation plays a crucial role not only in protein structure but also in cell-cell recognition, and perhaps even signaling mechanisms [6-8]. Therefore, the analysis of protein glycosylation is of the utmost importance if its biological roles are to be understood and evaluated. To adequately describe glycosylation, three pieces of information are required: (1) identification of the glycosylated proteins and peptides, (2) the site(s) of the glycosylation, and (3) the structure of the glycan [2]. Obtaining this information is challenging since the oligosaccharide modification is highly heterogeneous. There are no clearly defined mass shifts as those for oxidation, phosphorylation, or acetylation. And unlike other PTMs, a mass shift for glycosylation can greatly exceed that of the peptide altering elution properties.

Published online January 10, 2006

Address reprint requests to Dr. S. M. Peterman, Thermo Electron Corporation, 265 Davidson Ave., Suite 101, Somerset, NJ 08873, USA. E-mail: scott.peterman@thermo.com
The most common approach used to identify glycosylated peptides employs detection of diagnostic sugar oxonium-ion fragments on a single or triple quadrupole mass spectrometer [2, 3, 9-14]. The general method used to create diagnostic ions employs CID in either the source region (single quadrupole MS) or the collision cell of a triple quadrupole instrument resulting in dissociation of the oligosaccharide modification $[2,3,5$, 9-15]. Detection of the diagnostic sugar oxonium-ion fragments can be used to trigger additional scans without CID to obtain intact molecular weights. Carr and coworkers [10, 11, 13] and Dziegielewska et al. [16] have performed extensive analysis on numerous diagnostic ions generated by CID to evaluate optimal signals that can be used to signify glycopeptide elution from an LC separation. Typically, the diagnostic fragment ions used for precursor ion scanning include the oxonium ions of hexose (Hex) at $m / z$ 163, $N$-acetylhexosamine (HexNAc) at $m / z 204$, and hexose- $N$-acetylhexosamine (Hex-Hex$\mathrm{NAc}$ ) at $m / z$ 366. However, the specificity of using the above listed diagnostic fragment ions for glycopeptide detection has been called into question since other nonglycosylated peptides dissociated by CID may result in isobaric interferences to the characteristic reporter ions $[2,10]$.

An alternative method for identifying glycosylated 
peptides employs high-resolution/high-mass accuracy scanning provided by quadrupole time-of-flight (TOF) instruments to increase the selectivity for detecting precursor ions $[2,17,18]$. Jebanathirajah and coworkers [2] increased selectivity using a mass tolerance of \pm 0.02 $\mathrm{Da}$ for the detection of $\mathrm{m} / \mathrm{z} 163,204$, and 366 reporter ions of glycopeptides spiked into a complex digest mixture [2]. Once peptides are identified as glycosylated from the precursor ion scanning experiment (i.e., detection of $\mathrm{m} / \mathrm{z} 163,204$, or 366), a tandem mass spectral event is performed for sequencing information. The limitations associated with this approach lie in precursor ion scanning on a TOF instrument. The long scan times (50 $\mathrm{ms}$ at a step size of $1 \mathrm{Da}$ ) needed to analyze a mass range of $1000 \mathrm{Da}$ prohibits protein digest analysis on an LC time scale. Therefore, analyses are generally performed via direct infusion, which may lead to decreased sensitivity due to charge suppression from simultaneous ionization of the complex protein digest. In addition, the diagnostic ion intensity used to trigger subsequent mass spectral events originates from a single charge state of a single glycoform, which may be significantly attenuated compared to the nonglycosylated peptide response.

The experiments in this report, however, describe a novel method to sensitively and selectively identify glycopeptides on-line while simultaneously acquiring high-resolution/high-mass accuracy full-scan data and sequencing information using a hybrid linear ion trap / FT-ICR mass spectrometer. Our approach is to combine source CID with tandem mass spectral analysis of $\mathrm{m} / \mathrm{z}$ 204 and/or 366 diagnostic ion(s) in the linear ion trap to increase the detection capabilities without dramatically increasing experimental time. The increase in sensitivity is related to the physical attributes of a linear ion trap [19] (e.g., fast ion fill times, high trap capacity, dual orthogonal detection) that enable high-throughput analysis of complex peptide mixtures that have traditionally been relegated to multiple mass spectrometers for detection and characterization of glycopeptides. The above mentioned approach capitalizes on coelution of glycoforms, which results in simultaneous dissociation of all glycoforms in the source region to produce an increased diagnostic ion signal compared to activating a single glycoform as in a precursor ion scan. Thus, the short amount of time required to complete the pseudo$\mathrm{MS}^{3}$ survey scan enables subsequent full-scan and datadependent MS/MS experiments to be performed for characterization.

\section{Experimental}

\section{Chemicals and Reagents}

Dithiothreitol, iodoacetamide, formic acid, and bovine fetuin were purchased from Sigma (St. Louis, MO). The bovine fetuin was used without further purification. Trypsin was purchased from Promega (Madison, WI). The glycopeptide standard was purchased from EMD
Biosciences (San Diego, CA) as a lyophilized powder that contained a mixture of glycoforms on the base peptides GENR and NK originating from phospholipase $\mathrm{A}_{2}$ [honeybee (Apis mellifica) venom gland extracts] [20]. HPLC-grade acetonitrile and water were purchased from Burdick and Jackson (Muskegon, MI).

\section{Sample Preparation}

The glycopeptide standard was reconstituted in water to give a stock solution of $200 \mathrm{pmol} \mu \mathrm{L}^{-1}$. All dilutions were made from the stock solution with water and analyzed without further purification. A $1 \mathrm{mg} \mathrm{mL} \mathrm{m}^{-1}$ solution of bovine fetuin was digested with trypsin using a standard protocol [21]. Amounts reported on column are based on the stock solution from the glycopeptide standard mixture and the original amount used during the fetuin digestion. Dilutions of the enzymatic digestion were done using a $0.1 \%$ formic acid solution before injection.

\section{LC-MS and $M S^{n}$ Analysis}

HPLC. A binary solvent system composed of $\mathrm{H}_{2} \mathrm{O}$ containing $0.1 \%$ formic acid (A) and $\mathrm{MeCN}$ containing $0.1 \%$ formic acid (B) was used for all analyses. A flow rate of $50 \mu \mathrm{L} \mathrm{min}{ }^{-1}$ consisting of $20 \%$ organic phase was used for the analyses of the glycopeptide standard with a total run time of $3 \mathrm{~min}$. Five microliters were injected onto a BioBasic C18 column with the dimensions of 100 $\times 1 \mathrm{~mm}$ (Thermo Electron, Bellefonte, PA) for each analysis with five replicate injections per level.

The bovine fetuin digest analyses were analyzed using a gradient running from 5 to $45 \%$ B in $45 \mathrm{~min}$, holding at $45 \% \mathrm{~B}$ for three $\mathrm{min}$, then immediately increasing to $80 \%$ B for a column wash before column equilibration at $5 \%$ B for the next injection. A $10 \mu \mathrm{L}$ volume was injected per analysis.

Mass spectrometer. All analyses were performed on the Finnigan LTQ-FT hybrid linear ion trap/FT-ICR mass spectrometer (Thermo Electron, Bremen, Germany). A detailed schematic of the hybrid instrument has been described previously [22]. For all in-source collisioninduced dissociation analysis (source CID), a $92 \mathrm{~V}$ potential offset was applied to ion optics following the ion skimmer. Automatic gain control (AGC) target values for full-scan MS data acquisition were maintained at $5 \mathrm{e}^{5}$ counts for detection in the ICR cell and $3 \mathrm{e}^{4}$ counts for detection in the linear ion trap. AGC target values for MS/MS product ion detection were $5 \mathrm{e}^{5}$ and $1.5 \mathrm{e}^{4}$ counts for the ICR cell and linear ion trap, respectively. One microscan was used for all full-scan mass spectral data acquisition with the exception of MS/MS product ion detection in the ICR cell, where two microscans were used. A resolving power of 100,000 (at $u m / z 400$ ) was used for all ion detection in the ICR cell. 

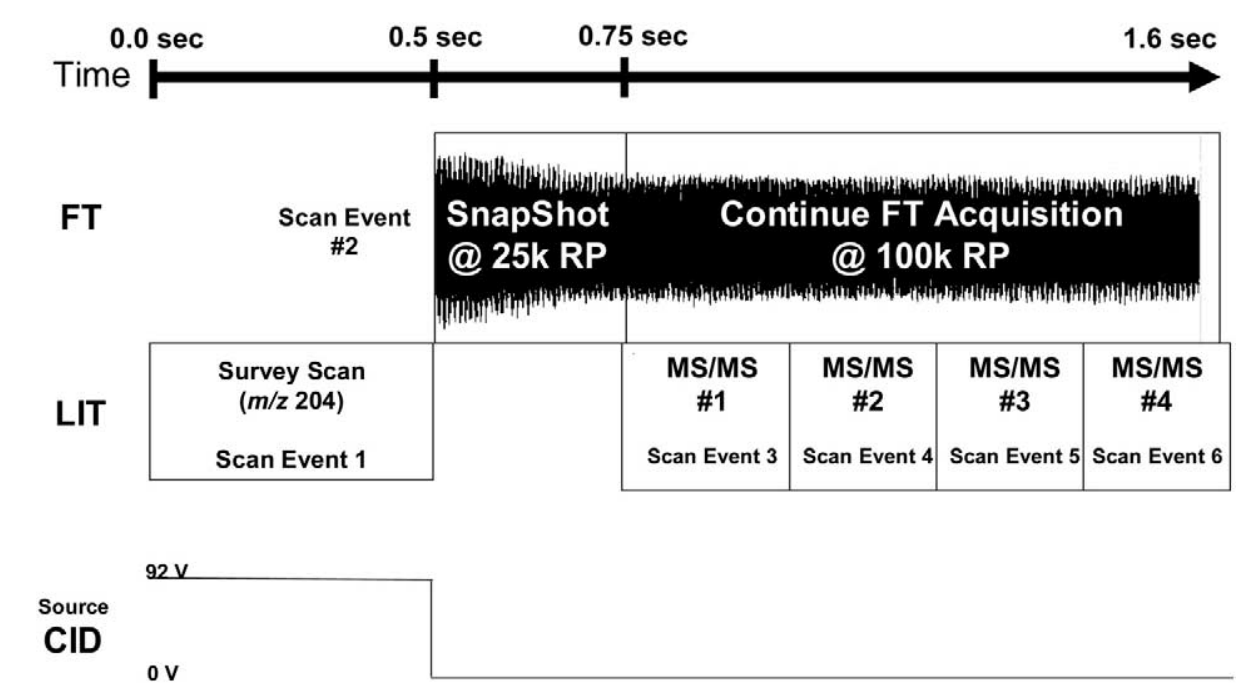

Figure 1. Plot of the approximate temporal relationship for the six scan events used for identifying and characterizing modified and unmodified enzymatic peptides in one analytical experiment. The FT refers to data acquisition in the ICR cell and LIT corresponds to linear ion trap detection.

Glycopeptide standard analysis. Initial analysis of the glycopeptide standard was performed using both the linear ion trap and the ICR cell for characterization and evaluation of conversion efficiency of intact glycopeptides to the diagnostic sugar fragments $\mathrm{m} / \mathrm{z} 204$ and 366 resulting from source CID. Subsequent ion detection in the ICR cell with and without source CID utilized the high-resolution/mass accuracy to confirm intact and fragmented glycopeptide structural assignments. The sensitivity of the pseudo-MS ${ }^{3}$ survey scan was compared to full-scan glycopeptide detection using integrated peak areas from reconstructed ion chromatograms.

Bovine fetuin digest analysis. The enzymatic digest of fetuin was analyzed using an experimental sequence consisting of six scan events. A temporal representation of the six scan event cycle and the site for the respective data acquisition are presented in Figure 1. A pseudoMS $^{3}$ survey scan was performed in scan event 1 with mass spectral data acquired in the linear ion trap. This scan employed $92 \mathrm{~V}$ of source CID enabling linear ion trap collection, isolation, and dissociation of the resulting diagnostic HexNAc $(\mathrm{m} / \mathrm{z} 204)$ ion in a true tandem MS analysis. Scan event 2 utilized the ICR cell to acquire a full-scan mass spectrum without source CID covering a mass range of 400 to $1800 \mathrm{Da}$. During the highresolution full-scan transient acquisition, a low-resolution (ca. 25,000 at $\mathrm{m} / \mathrm{z} 400$ ) snapshot is recorded and interrogated yielding mass-to-charge values for the subsequent data-dependent MS/MS mass analyses performed in scan events 3 to 6 . Parallel acquisition of the data-dependent MS/MS spectra was performed during the completion of the high-resolution mass spectral detection in scan event 2 to maximize experimental cycle time and provide sequence coverage. Source CID was not employed for scan events 2 to 6 . In addition, Dynamic Exclusion was employed to increase peptide coverage using a repeat count of 1 . That is, once a precursor mass-to-charge value was identified and used to trigger a data-dependent MS/MS event, the precursor mass-to-charge value was placed on an exclusion list for $20 \mathrm{~s}$ to eliminate triggering an additional datadependent event on the same mass-to-charge value. The resulting MS/MS data were analyzed using Bioworks version 3.2 (Thermo Electron, Bremen, Germany) to identify unmodified peptides [23]. The search criterion used to initially match in silico enzymatic peptides to experimentally determined peptide molecular weights was set to $5 \mathrm{ppm}$ to provide additional confidence in the Bioworks search output.

Qualitative analysis of the glycopeptides was done using two different programs. First, the program Xtract (Thermo Electron, Bremen, Germany) was used to convert the raw data into singly charged monoisotopic spectra for easy interpretation of protonated molecular ions. Then, the reported accurate mass of the protonated molecular ion was used to search possible oligosaccharide structures and compositions using GlycoMod (http:/ / us.expasy.org/cgi-bin/glycomod.pl) from the Swiss-Prot website [24, 25]. Glycopeptides and glycoforms previously reported by Medzihradszky et al. were used for comparison and confirmation $[6,26]$.

\section{Results and Discussion}

The utility of performing precursor ion scanning for detection of glycopeptides is particularly attractive since glycopeptide fragmentation yields predominantly $\mathrm{N}$-acetylhexosamine (HexNAc) or hexose- $\mathrm{N}$-acetylhexosamine (Hex-HexNAc) following collision-induced dissociation, making it essentially universal for glycopeptide detection. However, precursor ion scanning is a slow, relatively insensitive technique due to the poor duty cycle that results from scanning Q1. In addition, its 


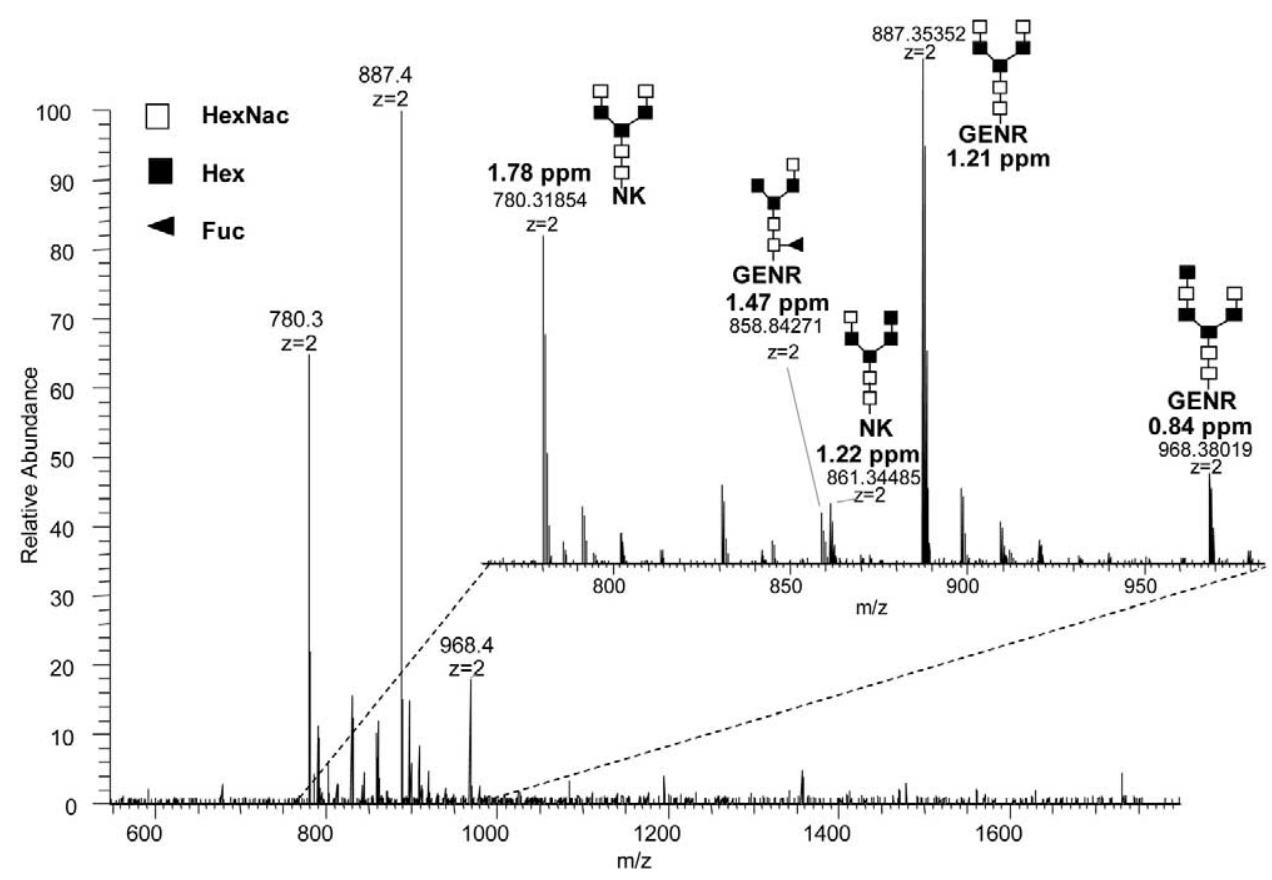

Figure 2. High-resolution full-scan mass spectrum acquired in the ICR cell for the glycopeptide standard mixture. The expanded mass region displays the multiple glycoforms present in the sample with the predicted oligosaccharide structure. The open squares represent HexNAc, filled squares represent Hex, and filled triangles represent fucose. The calculated mass measurement errors for the monoisotopic peak for the observed +2 charge states are in reference to the theoretical structure presented.

selectiveness for glycopeptide identification without high-resolution capabilities has been called into question [2]. Yet, it offers the advantage of identifying the mass-to-charge ratio of each of the glycoforms present. To improve upon precursor ion scanning, a new method would need to be faster, more sensitive, and/or add selectivity. All three of these attributes can be found in a combined source CID, tandem MS approach to detecting glycopeptides.

Generating diagnostic oxonium ions from glycopeptides in the skimmer region of a mass spectrometer has been well described in the literature [5, 10, 14, 27]. In brief, a high potential is placed on the ion optics following the skimmer, such that ions are accelerated in a region that has moderate pressure, causing ion fragmentation. A primary limitation associated with source CID is the lack of selectivity as to which ions are fragmented. However, for the analysis of glycopeptides, this feature can be a positive attribute. Under reverse phase LC conditions, glycopeptides typically are present as multiple coeluting glycosylated forms of different mass and/or charge states [18]. Employment of source CID to identify glycopeptide elution is an attractive proposition because of this coelution of glycoforms. Since ion activation is accomplished in the high-pressure region of the ion stack, all ions formed at a given retention time are subjected to collision-induced dissociation. Thus, multiple glycoforms can contribute to the intensity of the diagnostic oxonium ions simultaneously. Taking advantage of the nonselective nature of source CID to produce more $\mathrm{m} / \mathrm{z} 204$ and 366 diagnostic fragment ions enables greater sensitivity than attempting to fragment and detect each glycoform independently, as is the case in a precursor ion scan.

\section{Glycopeptide Standard Mixture Results}

Preliminary studies used to evaluate the survey scan for identification of glycopeptides at varying concentrations were performed on a standard containing glycoforms of two peptides with the amino acid compositions NK and GENR, where the oligosaccharide motif constitutes ca. $1200 \mathrm{Da}$ [20]. The large mass difference between the amino acid backbone and the oligosaccharide modification results in the sugar modification dominating chromatographic properties. That is, all glycoforms were observed coeluting immediately following the void volume despite using a mobile phase composition of $20 \%$ organic. Figure 2 shows a full-scan spectrum for ca. 1 pmol of the glycopeptide mixture acquired in the ICR cell. The inset shows that all glycopeptides are present in the +2 charge state with five different glycoforms being identified using high mass accuracy and multiple stages of $\mathrm{MS}^{\mathrm{n}}$ (data not shown). For example, the base peak component $(\mathrm{m} / \mathrm{z}$ 887.4) was identified as containing the peptide backbone GENR glycosylated with $\mathrm{HexNAc}$ - $-\mathrm{Hex}_{3}$ and the $\mathrm{m} / \mathrm{z} 780.3$ ion was identified as the dipeptide NK modified with the same oligosaccharide. The average mass error for the five glycopeptides was $1.16 \mathrm{ppm}$. 

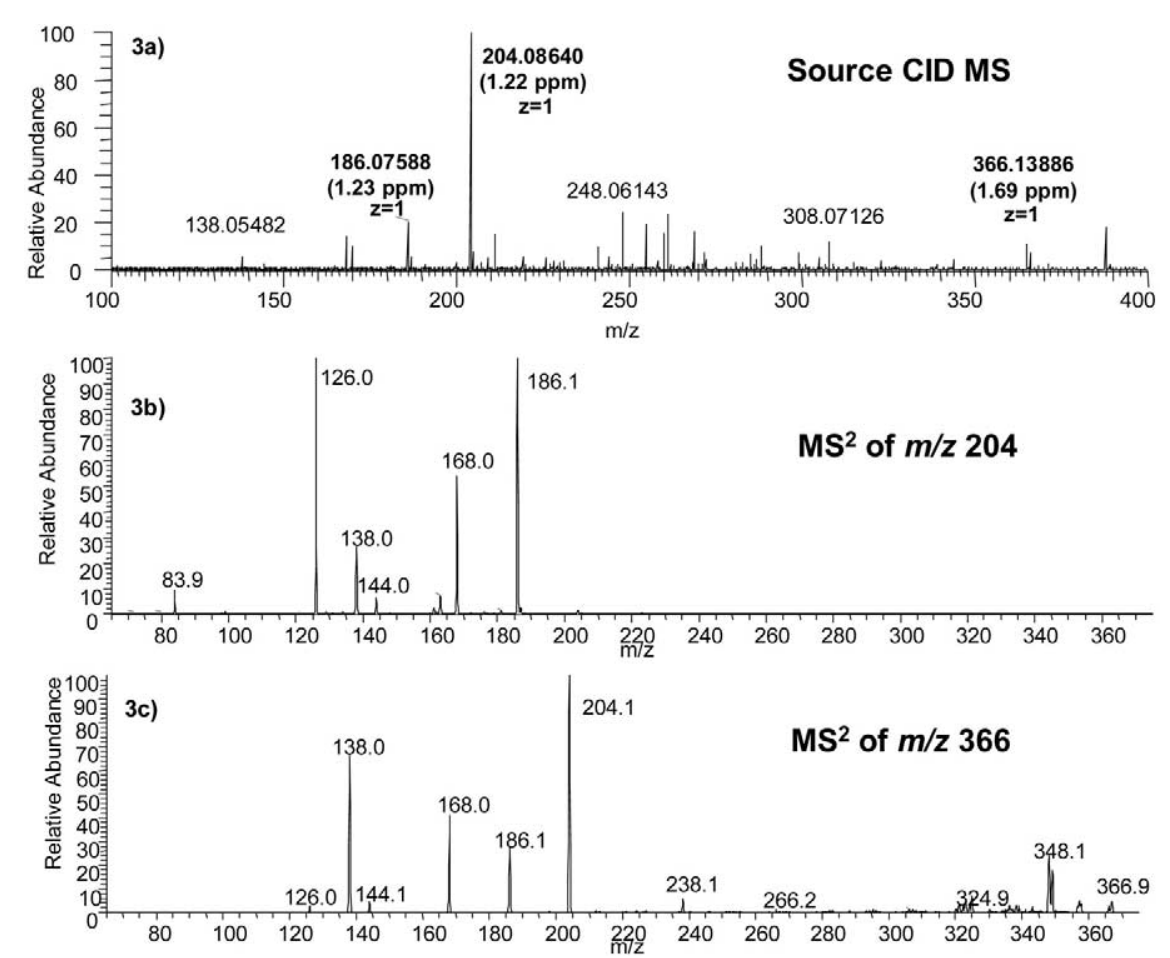

Figure 3. Full-scan and $\mathrm{MS}^{2}$ mass spectra of diagnostic oxonium ions acquired using in-source CID of $92 \mathrm{~V}$ from the glycopeptide standard mixture. (a) FT-ICR detection for the low mass region (100-400 $\mathrm{Da})$ with mass errors listed. The tandem mass spectra for both the HexNAc ion at $m / z 204$ (b) and the Hex-HexNAc ion at $m / z 366$ (c) acquired in the linear ion trap are displayed.

Following characterization of the glycopeptide standard mixture, source CID was performed to generate the diagnostic oxonium ions. Previous work on a 3-D ion trap instrument showed that source parameters had to be altered to produce strong diagnostic oxonium ions [27]. For example, optimal settings reported for the tube lens and capillary voltage used to generate strong diagnostic oligosaccharide ion signals were 100 and 75 $\mathrm{V}$, respectively, compared with standard operating parameters of 10 and $30 \mathrm{~V}$. In addition, the capillary temperature was increased from $130^{\circ}$ to $175^{\circ}$. Results obtained on the linear ion trap in the current studies showed that substantial signal for $m / z 204$ was obtained by simply setting the source CID offset to $92 \mathrm{~V}$ with no adjustment to the capillary temperature. Figure $3 a$ shows a high-resolution full-scan mass spectrum of the glycopeptide standard mixture for the low mass range (100-400 Da) with source CID employed. The base peak in the spectrum is the $\mathrm{m} / \mathrm{z} 204$ ion, which is directly attributed to the $\mathrm{C}_{8} \mathrm{H}_{14} \mathrm{NO}_{5}{ }^{+}$ion representing $\mathrm{N}$-acetylhexosamine (HexNAc). In addition, two other characteristic sugar fragments are observed at $\mathrm{m} / \mathrm{z} 366$ (HexHexNAc) and $m / z 186\left(\mathrm{HexNAc}-\mathrm{H}_{2} \mathrm{O}\right)$. Each of the diagnostic fragment ions had measured mass accuracies of $1.7 \mathrm{ppm}$ or less for the proposed elemental compositions giving high confidence in the correct identification. In fact, even increasing the mass tolerance to 5 ppm would not result in a plausible secondary ion composition.
It is clear from the full-scan mass spectrum displayed in Figure $3 \mathrm{a}$ that there are numerous product ions formed in addition to the $\mathrm{m} / \mathrm{z} 204$ and 366 diagnostic ions during source CID. The chemical background generated by source CID may limit the sensitivity and dynamic range for the detection of the diagnostic ions since the ion trap mass spectrometer operates using automatic gain control (AGC) to limit the number of ions that are collected for each mass spectrum. While using a 3-D ion trap to detect diagnostic oxonium ions generated by source CID, Sullivan et al. [27] found that they achieved the best sensitivity by utilizing SIM mode. This is not surprising since SIM and MS ${ }^{n}$ modes on an ion trap mass spectrometer increase the sensitivity and dynamic range of the instrument by overfilling the trap and then isolating the correct amount of the ions of interest using a waveform. Unfortunately, the use of SIM mode does not add any selectivity to the source CID experiment. That is, during the elution of an enzymatic digest, nonglycosylated peptides may dissociate to form a $m / z 204$ or 366 product ion that is not an oxonium ion, resulting in a false positive for glycopeptides [2]. Although the method employed by Sullivan et al. using diagnostic ion detection by SIM showed evidence of glycopeptide elution, the method showed much greater promise following protein treatment with neuramidase to dramatically reduce the glycopeptide complexity. To achieve greater selectivity without the use of neuramidase, a source CID MS/MS scan (pseu- 
(a)

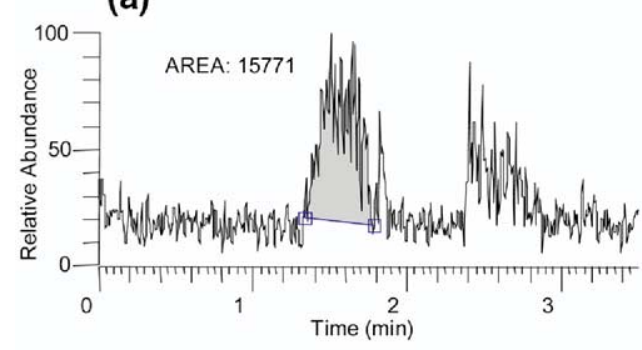

(c)

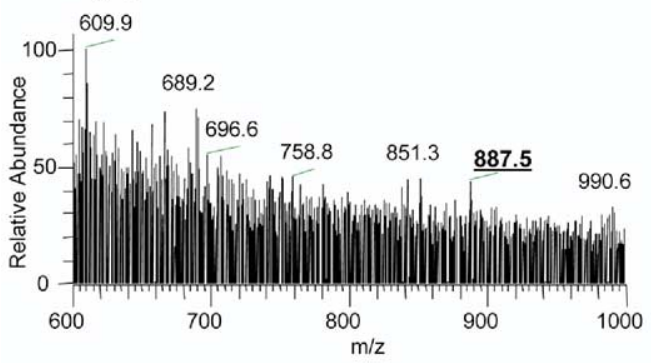

(b)

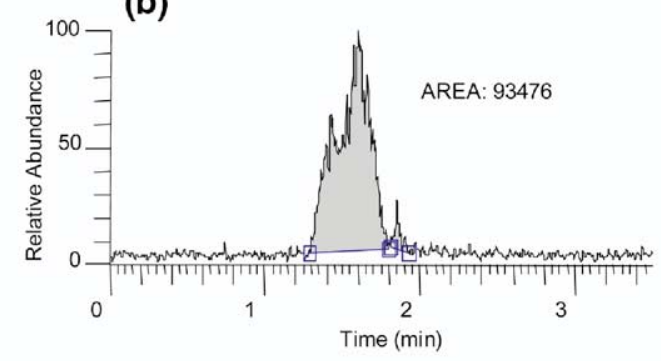

(d)

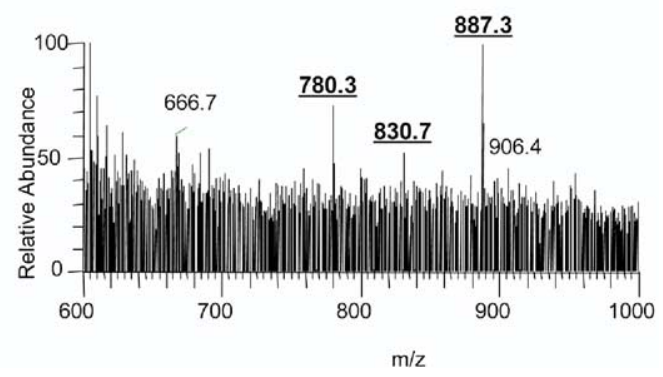

Figure 4. Extracted ion chromatogram for the $\mathrm{m} / \mathrm{z} 887$ ion from the glycopeptide standard mixture at (a) 25 and (b) $250 \mathrm{fmol}$ injected on column. The average full-scan mass spectrum for each level is displayed in (c) $25 \mathrm{fmol}$ and (d) $250 \mathrm{fmol}$. All data were acquired in the linear ion trap. The mass-to-charge values for known glycoforms are underlined.

do-MS ${ }^{3}$ for the $m / z 204$ or 366 diagnostic ions is used for the basis of our approach to glycopeptide detection.

Performing a true tandem mass spectral event in the linear ion trap following source CID dramatically increases sensitivity and selectivity by first isolating the $\mathrm{m} / \mathrm{z} 204$ product ion (or $\mathrm{m} / \mathrm{z} 366$ ), then using identification of known tandem mass spectral product ions for glycopeptide confirmation. Figure 3 shows an MS/MS spectrum for the (Figure 3b) $\mathrm{m} / \mathrm{z} 204$ and (Figure 3c) $\mathrm{m} / \mathrm{z}$ 366 diagnostic sugar ions following source CID. Each tandem mass spectrum was acquired in the linear ion trap using one microscan resulting in ca. $0.5 \mathrm{~s}$ of acquisition time. Note the low background signal from the MS/MS spectra with only product ion detection from the $\mathrm{m} / \mathrm{z} 204$ and 366 precursor ions. The relative abundance of the $\mathrm{m} / \mathrm{z} 366$ precursor ion was only $10 \%$ of the $m / z 204$ base peak observed in Figure 3a, yet a clean and rich product ion spectrum dominated by a $\mathrm{m} / \mathrm{z} 204$ product ion. The pseudo-MS ${ }^{3}$ product ions can then be used for post-acquisition filtering to identify glycopeptide elution, or online as an SRM for fraction collecting. Although the source CID event in the linear ion trap mass spectrometer is not as selective as a precursor scan on a triple quadrupole, the subsequent MS/MS event in the linear ion trap provides the necessary selectivity to confirm the presence of glycopeptide elution.

Determination of glycopeptide detection capabilities using a pseudo-MS ${ }^{3}$ survey scan was performed on the standard glycopeptide mixture. Previous means of identifying glycopeptides in an ion trap utilized datadependent MS/MS scanning triggered from the prior full-scan mass spectrum [4, 28]. Since this has been the primary method for characterizing glycopeptides using ion traps, full-scan mass spectral detection capabilities were compared to results using the combination source CID-MS/MS approach. Figure 4 shows two extracted ion chromatograms for the $\mathrm{m} / \mathrm{z} 887$ ion and the corresponding full-scan mass spectrum at the elution maximum of the standard glycopeptide mixture. The two levels displayed correspond to $25 \mathrm{fmol}$ (Figure 4a), and $250 \mathrm{fmol}$ (Figure $4 \mathrm{~b}$ ) on column. Note that the retention times are directly following the void volume of the C18 column despite a mobile phase composition of $20 \%$ organic. The full-scan mass spectra presented in Figure 4c showed a minor peak at $\mathrm{m} / \mathrm{z} 887$ for $25 \mathrm{fmol}$ of the standard glycopeptide mixture on column but no other glycoform could be identified. The signal intensity of the $m / z 887$ ion would be difficult for data-dependent scanning to select and perform automated tandem mass spectral data acquisition because of the relative intensity of the $\mathrm{m} / \mathrm{z} 887$ ion to that of the background. Consequently, omitting the precursor glycopeptide mass from data dependent MS/MS analysis would significantly decrease identification capabilities. Figure $4 \mathrm{~b}$ shows the extracted ion chromatogram for the $\mathrm{m} / \mathrm{z}$ 887 ion with $250 \mathrm{fmol}$ on column. The integrated peak for the $\mathrm{m} / \mathrm{z} 887$ ion is significantly greater than the background. The mass spectrum (Figure 4d) shows not only the primary $N$-linked glycopeptide (GENR), but the $m / z 780$ and 830 representing $N$-linked glycoforms of NK. At $250 \mathrm{fmol}$ on column, the ion intensity for the $\mathrm{m} / \mathrm{z} 887$ and 780 precursor ions would be sufficient to trigger a data-dependent MS/MS event. 
$25 \mathrm{fmol}$

(a)
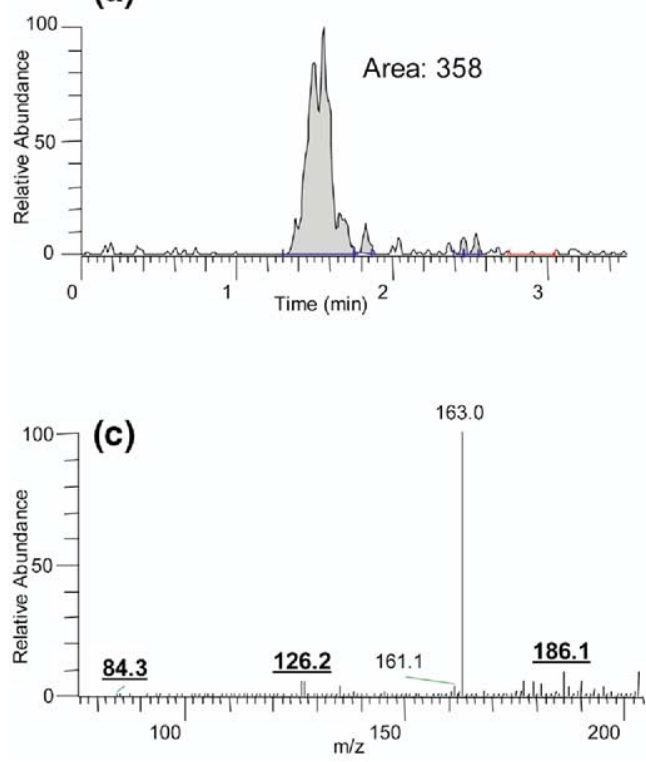

$250 \mathrm{fmol}$

(b)
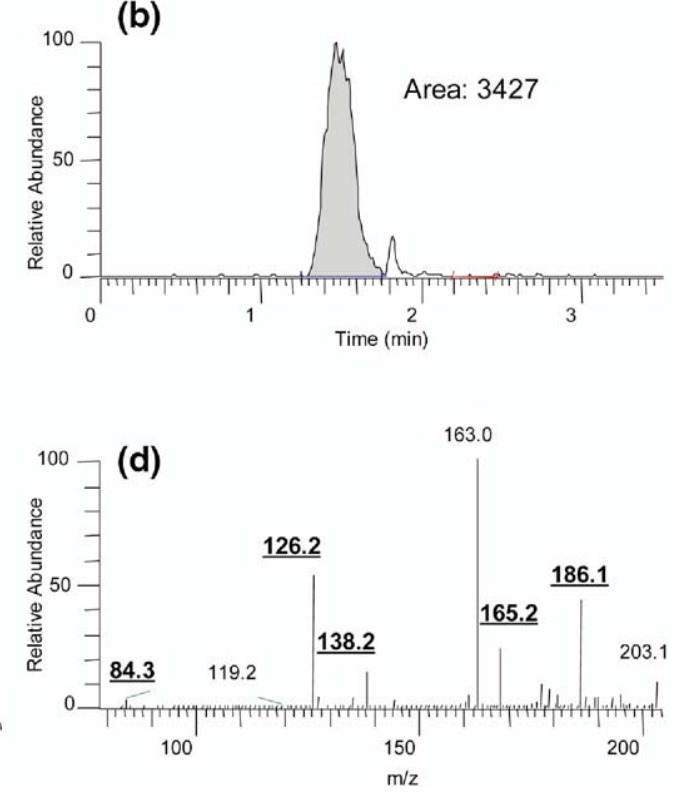

Figure 5. Extracted ion chromatograms for the summation of $m / z 126$ and 186 product ions generated by the pseudo-MS ${ }^{3}$ survey scan of the diagnostic oxonium ion at $\mathrm{m} / \mathrm{z} 204$ from the glycopeptide standard mixture at (a) $25 \mathrm{fmol}$ and (b) $250 \mathrm{fmol}$ injected on column. All ion detection was performed in the linear ion trap. The full-scan tandem mass spectra for each level is shown below the corresponding level injected. Known product ions from HexNAc are underlined.

The above experiment was repeated employing source CID (92 V) and performing tandem mass spectral analysis of $m / z$ 204. Figure 5 shows the extracted ion chromatogram for the summation of $\mathrm{m} / \mathrm{z} 126$ and 186 MS/MS product ions for $25 \mathrm{fmol}$ (Figure 5a) and 250 fmol (Figure $5 b$ ) of the standard glycopeptide mixture injected on column. Figure $5 c$ shows the resulting full-scan product ion spectrum of $\mathrm{m} / \mathrm{z} 204$ acquired at the apex of the elution peak. The $m / z 163$ base peak ion results from a chemical interference in the $\mathrm{m} / \mathrm{z} 204$ isolation window. Despite the interference from the $\mathrm{m} / \mathrm{z}$ 163 ion, an integrated chromatographic peak can be reconstructed using the $\mathrm{m} / \mathrm{z} 126$ and 186 product ions, which were only $5 \%$ of the base peak. Thus, the selectivity of utilizing a pseudo-MS ${ }^{3}$ survey scan can be dramatically improved when filtering the $\mathrm{MS}^{2}$ data for known product ions of the HexNAc oxonium ion at $\mathrm{m} / \mathrm{z}$ 204.

Figure $5 \mathrm{~b}$ shows the extracted ion chromatogram for the $\mathrm{m} / z 126$ and 186 ions for $250 \mathrm{fmol}$ on column. The integrated peak area was calculated to be 9.6 times greater than that for the peak area for $25 \mathrm{fmol}$ on column, indicating a great potential for quantitative experiments to be performed. Figure $5 \mathrm{~d}$ shows the survey scan for $250 \mathrm{fmol}$ on column. The underlined product ions correspond to diagnostic fragments for the HexNAc oxonium ion. Note that all of the product ions displayed in Figure $3 b$ are present in Figure $5 d$ even though the amount on column has been reduced by a factor of four.

\section{Fetuin Analysis Results}

Analysis of more complex mixtures of modified and native peptides was done using an enzymatic digestion of fetuin. Fetuin is ideally suited to determine the effectiveness of the pseudo-MS ${ }^{3}$ survey scan because of the high degree of glycosylation. In addition, bovine fetuin has been well studied, with the sequence and oligosaccharide modifications published [6, 12, 26, 29]. Figure 6a shows a base peak plot for the enzymatic digest of fetuin with the peptide map associated to the corresponding elution peaks. A base peak plot is used to represent the ion intensity of the most intense fullscan MS ion at each point in the chromatogram and generally yields a more interpretable chromatogram. The fetuin sequence used for the peptide mapping was that published by Medzihradszky et al. [26] Figure 6b shows the extracted ion chromatogram for the $\mathrm{m} / z 126$ product ion following source CID and MS/MS analysis of the $\mathrm{m} / \mathrm{z} 204$ diagnostic HexNAc ion detected in the linear ion trap. Glycopeptide assignments resulted from full-scan accurate mass data comparison with reported structures from previous publications $[6,26]$. Note that the intense peaks in Figure 6b identified as glycopeptides correspond to peaks with low relative intensity in Figure 6a. For example, the base peak in Figure $6 \mathrm{~b}$ identified as the $N$-linked glycopeptide $\mathrm{T}_{127-141}$ eluting at $15.5 \mathrm{~min}$ has a relative abundance of ca. $10 \%$ to the $\mathrm{T}_{11-32}$ peptide eluting at $15.8 \mathrm{~min}$ shown in Figure 6a.

Figure $6 \mathrm{c}$ shows an extracted ion chromatogram 


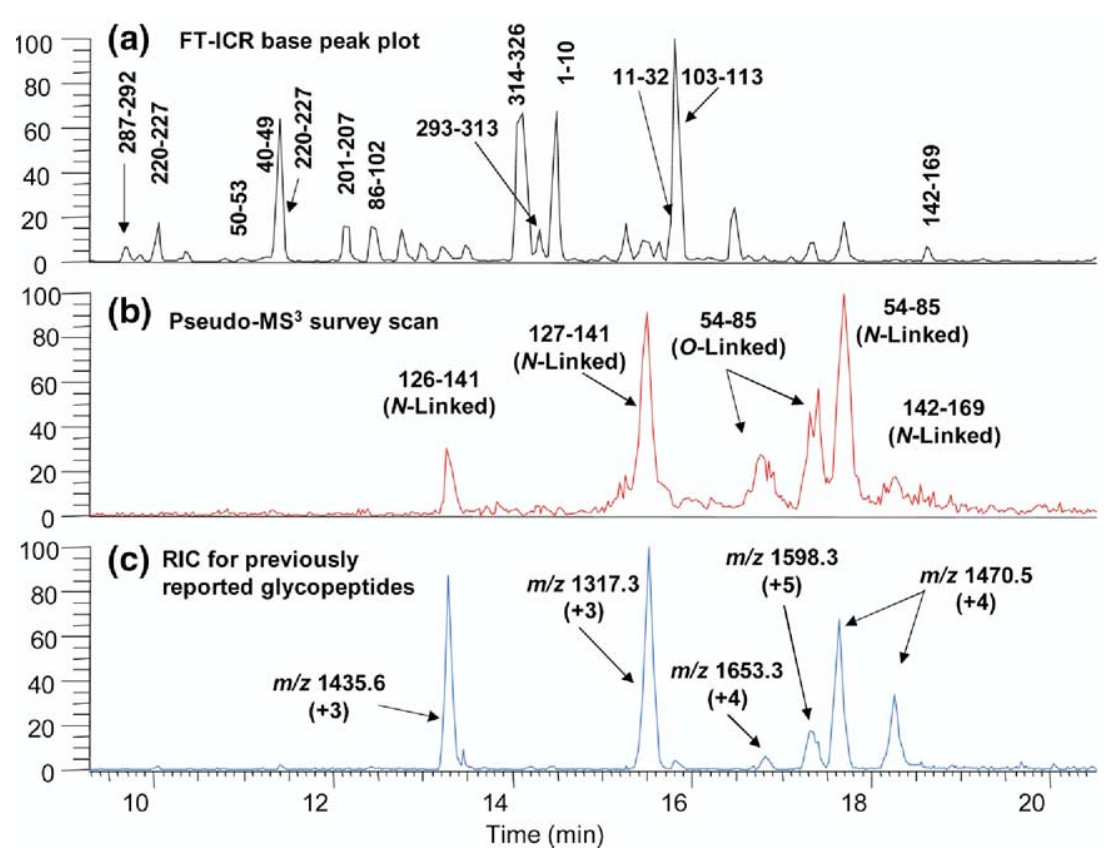

Figure 6. Base peak plot and extracted ion chromatograms for the enzymatic digest of bovine fetuin describing the peptide and glycopeptide elution profiles. The FT-ICR base peak plot is shown in (a) for unmodified peptides. The pseudo-MS ${ }^{3}$ survey scan results indicating the elution of glycopeptides are depicted as an extracted ion chromatogram for the $m / z 126$ product ion from the HexNAc ion (b). (c) Illustrates where the previously reported glycopeptide ions of bovine fetuin were eluting as a summation of extracted ions from the literature. Note the agreement between (b) and (c).

compilation for each of the five fetuin glycopeptides reported from Medzihradszky et al. The ions used to construct the chromatographic trace for Figure 6c represents each of the proposed $\mathrm{N}$ - and $\mathrm{O}$-linked glycopeptides and are labeled with the corresponding mass-tocharge value, and predominant charge state detected from the full-scan mass analysis in the ICR cell. All extracted ion chromatograms for the proposed glycopeptides of fetuin align with the primary peaks identified using the pseudo-MS ${ }^{3}$ survey scan (Figure 6b). The excellent agreement between the proposed glycopeptides (Figure 6c) and the experimentally identified glycopeptides (Figure 6b) demonstrates that excellent selectivity is achieved using a pseudo-MS ${ }^{3}$ survey scan approach without enzymatically releasing sialic acids before mass spectral analysis.

Since the survey scan does not acquire the high mass range, a full-scan mass spectrum without source CID is acquired directly following the survey scan. The subsequent full-scan spectra enable determination of intact peptide masses at the chromatographic elution of the diagnostic HexNAc ions. Using only a source CID offset voltage for generation of the diagnostic sugar ions enables optimum spraying conditions for full scan mass analysis in the same analytical experiment.

The elution time at $17.7 \mathrm{~min}$ is a good representation of the time requirements to complete all six scan events while a suspected glycopeptide is eluting. A total of $1.7 \mathrm{~s}$ of experimental time was needed to acquire a pseudo-MS ${ }^{3}$ survey scan and a full-scan mass spectrum.
The ion flux of the eluting glycopeptides does not change significantly during the $0.5 \mathrm{~s}$ needed for survey scan acquisition so the subsequent MS and MS/MS events give a good reflection of the intact precursor ions detected in the survey scan. In addition, parallel detection of four full-scan data-dependent MS/MS scans were acquired in the same $1.2 \mathrm{~s}$ as that for highresolution/accurate mass data acquisition. The resulting MS/MS spectra were used to sequence the $N$-linked sugar moiety of the +4 and +5 charge states for each of the $N$-linked glycoforms of residues $\mathrm{T}_{54-85}$ eluting at $17.7 \mathrm{~min}$. Figure 7 shows a high-resolution/high-mass accuracy full-scan mass spectrum for the elution peak identified as the $\mathrm{T}_{54-85}$ glycopeptide containing $\mathrm{Hex}_{5} \mathrm{HexNAc}_{4} \mathrm{Neu}_{5 \mathrm{Ac}_{3}}(\mathrm{~m} / \mathrm{z} 1176.7$ for the +5 charge state and $\mathrm{m} / \mathrm{z} 1470.7$ for the +4 charge state) and

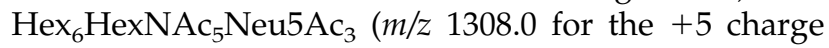
state and $\mathrm{m} / \mathrm{z} 1634.7$ for the +4 charge state). The peptide sequence and oligosaccharide structures used for each labeled glycoform were adapted from previously reported structures. The monoisotopic peak for each ion is labeled with the corresponding mass accuracy. Note that the mass errors reported are better than 2 ppm using external calibration regardless of the relative ion abundance. The survey scan, which was acquired directly before the full-scan mass spectrum, is shown in the inset. The diagnostic HexNAc fragment ions are labeled and contain all of the same fragment ions as that detected for the glycopeptide standard mix shown in Figure $3 b$ despite a different oligosaccharide 


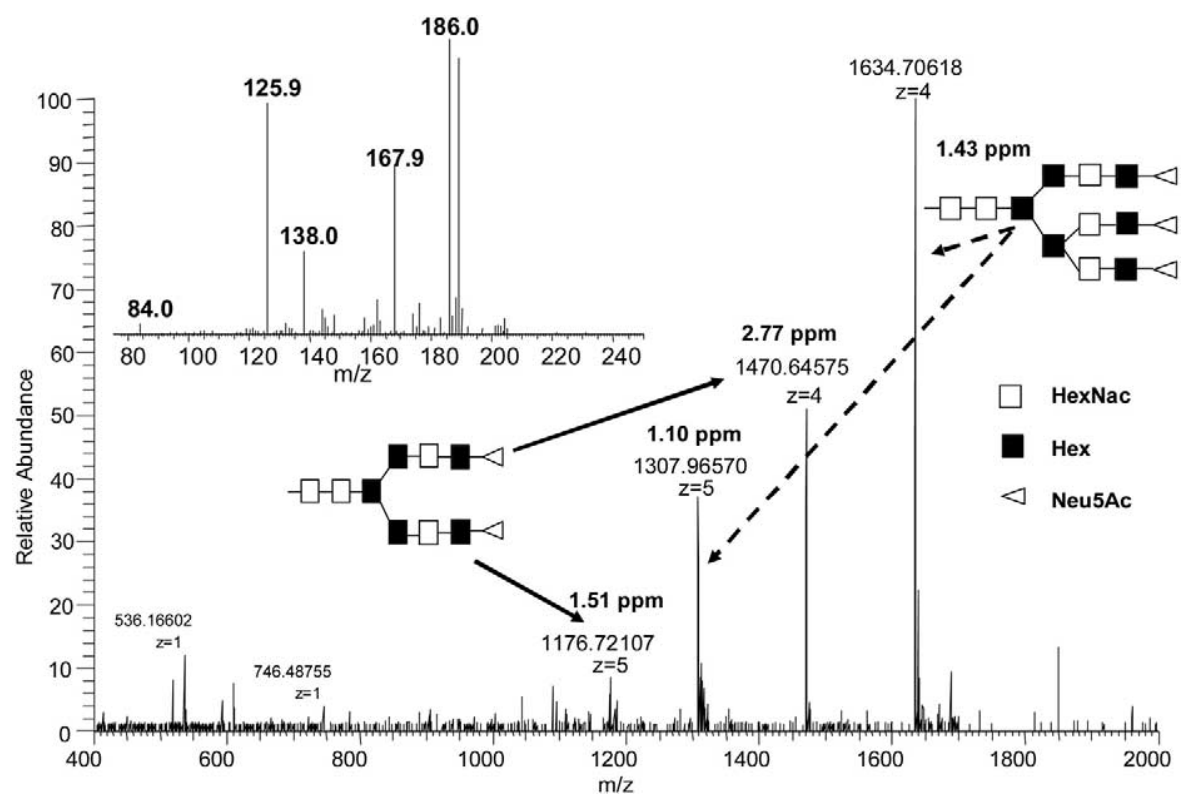

Figure 7. Full-scan mass spectrum for the retention time of $17.6 \mathrm{~min}$ showing two $\mathrm{T}_{54-85}$ glycoforms with the oligosaccharide structures and mass accuracies listed. The open squares represent HexNAc, filled squares represent Hex, and open triangles represent Neu5Ac. The inset shows the survey scan acquired directly before the high-resolution/high-mass accuracy spectrum acquisition showing the relative intensity of the characteristic fragment ions from HexNAc.

composition than that of the $\mathrm{m} / \mathrm{z} 887$ glycopeptide standards that was used for method development work.

In addition to the survey scan and high-resolution/ mass accuracy spectrum acquired for the identification of the glycoforms for the $\mathrm{T}_{54-85}$ peptide, oligosaccharide sequencing was accomplished during the parallel data- dependent MS/MS events. Figure 8 shows the resulting full-scan MS/MS spectra for the +4 charge state precursor ions of the $T_{54-85}$ glycoforms $\mathrm{m} / \mathrm{z} 1470$ and $\mathrm{m} / \mathrm{z}$ 1634 , for comparison. Using the parallel detection capability of the LTQ-FT, the product ion spectra were acquired in the linear ion trap while the full-scan mass detection occurred in the ICR cell to decrease the total
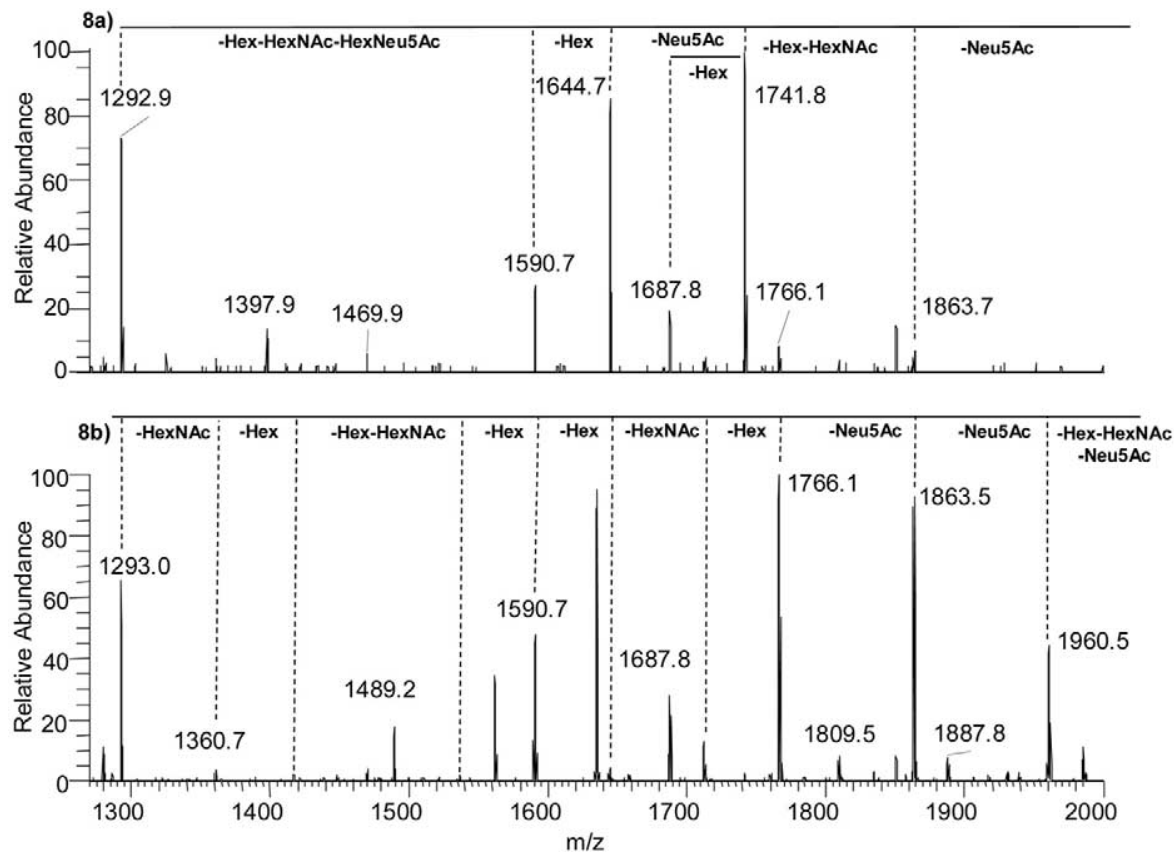

Figure 8. Full-scan data-dependent MS/MS spectra for the (a) $m / z 1470$ and (b) $m / z 1635$ glycopeptide precursor ions acquired in the linear ion trap. 
Table 1. List of the identified glycopeptides and corresponding glycoforms for the N- and O-linked oligosaccharides from the enzymatic digestion of bovine fetuin. The molecular weight of the $[\mathrm{M}+\mathrm{H}]^{+}$used for the experimental mass was calculated using Xtract. The reported relative abundance and observed retention time (R.T.) from the apex of the corresponding elution peak is presented

\begin{tabular}{|c|c|c|c|c|c|}
\hline Sequence (oligosaccharide composition) & Position & $\begin{array}{l}\text { R. T. } \\
(\min )\end{array}$ & $\begin{array}{l}\text { Experimental } \\
\text { mass }\end{array}$ & $\begin{array}{l}\text { Theoretical } \\
\text { mass }\end{array}$ & $\begin{array}{r}\text { Mass } \\
\text { error } \\
\text { (ppm) }\end{array}$ \\
\hline $\mathrm{KL}^{*} \mathrm{CPD}{ }^{*} \mathrm{CPLLAPLNDSR}$ & $126-141$ & & & & \\
\hline 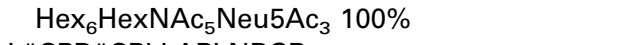 & & 13.27 & 4729.93994 & 4729.93576 & 0.884 \\
\hline$L^{*} C P D * C P L L A P L N D S R$ & $127-141$ & & & & \\
\hline 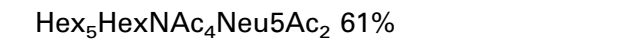 & & 15.50 & 3945.61597 & 3945.61319 & 0.706 \\
\hline $\mathrm{Hex}_{6} \mathrm{HexNAc}_{5} \mathrm{Neu}_{5} \mathrm{Ac}_{3} \quad 100 \%$ & & 15.51 & 4601.84082 & 4601.84080 & 0.004 \\
\hline 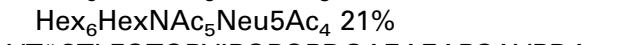 & & 15.51 & 4892.93604 & 4892.93622 & 0.037 \\
\hline $\begin{array}{l}\text { VT*CTLFQTQPVIPQPQPDGAEAEAPSAVPDA- } \\
\text { AGPTTPSAAGPPVASVVVGPSVVAVPLPLHR }\end{array}$ & 228-288 & & & & \\
\hline 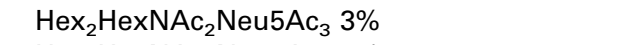 & & 16.76 & 7620.70898 & 7620.68980 & 2.52 \\
\hline 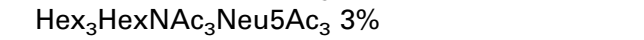 & & 16.76 & 7983.79395 & 7983.81529 & 2.67 \\
\hline $\mathrm{Hex}_{3} \mathrm{HexNAc}_{3} \mathrm{Neu}_{5 \mathrm{Ac}_{4}} 2 \%$ & & 17.30 & 8274.92969 & 8274.91070 & 2.29 \\
\hline RPTGEVYDIEIDTLETT *CHVLDPTPLAN ${ }^{*}$ CSRV & $54-88$ & & & & \\
\hline 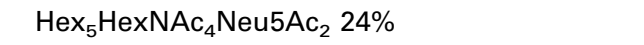 & & 17.69 & 5876.55371 & 5876.54042 & 2.26 \\
\hline $\mathrm{Hex}_{6} \mathrm{HexNAc}_{5} \mathrm{Neu}_{5 \mathrm{Ac}_{3}} 100 \%$ & & 17.69 & 6532.77930 & 6532.76804 & 1.72 \\
\hline 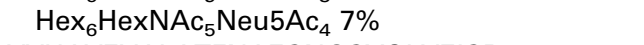 & & 17.69 & 6823.86279 & 6823.86345 & 0.100 \\
\hline VVHAVEVALATFNAESNGSYQLVEISR & $142-169$ & & & & \\
\hline 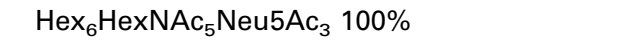 & & 18.27 & 5877.57422 & 5877.57388 & 0.058 \\
\hline
\end{tabular}

cycle time of the experiment. The reticle at the top of each figure is used to identify fragment ions resulting in the characterization of each oligosaccharide modification. Note the number of similar product ions resulting from each glycoform analyzed such as the $\mathrm{m} / \mathrm{z} 1293$, $1591,1688,1766$, and 1864 ions indicating a similar core oligosaccharide structure. From the tandem mass spectra, a total of two sialic acids were associated to the oligosaccharide motif linked to the $\mathrm{m} / \mathrm{z} 1470$ glycoform and three for the $\mathrm{m} / \mathrm{z} 1634$ glycoform.

An additional LC-MS/MS/MS analysis was performed employing product ion detection in the ICR cell for high-resolution/high-mass measurement accuracies for confirmation of product ion assignment (data not shown). Measured mass accuracies for similar product ions resulting from $\mathrm{m} / \mathrm{z} 1470$ and 1635 ions can be used for further confirmation of glycoform compositions. For example, the $\mathrm{m} / \mathrm{z} 1293$ product ion identified as the peptide backbone and a $\mathrm{N}$-acetylhexosamine has a measured mass accuracy of $1.76 \mathrm{ppm}$ resulting from the $\mathrm{m} / \mathrm{z} 1470$ precursor ion analysis compared with 1.93 $\mathrm{ppm}$ from the $\mathrm{m} / \mathrm{z} 1635$ ion as well as accuracies of 0.57 and $1.88 \mathrm{ppm}$ for the $\mathrm{m} / \mathrm{z} 1590.7$ product ion from $\mathrm{m} / \mathrm{z}$ 1470 and 1635, respectively, resulting in high confidence in the assignment of $\mathrm{T}_{54-85}+\mathrm{HexNAc}_{3} \mathrm{Hex}_{3}$.

Table 1 summarize the glycopeptides and corresponding glycoforms from the enzymatic digest of fetuin identified via the pseudo-MS ${ }^{3}$ survey scan analysis. The protonated molecular masses were calculated using Xtract and compared with the predicted theoretical chemical formula. In addition, the relative ion abundance of the protonated molecular ion detected at the apex of the reconstructed elution peak for each glycoform is listed. The mass accuracies for all of the glycoforms identified were better than $3 \mathrm{ppm}$ using the monoisotopic masses for the singly charged species. In fact, only the $O$-linked glycopeptides $\mathrm{T}_{228-288}$ and the $\mathrm{N}$-linked glycopeptide $\mathrm{T}_{54-85}$ containing the oligosaccharide $\mathrm{Hex}_{5} \mathrm{HexNAc}{ }_{4} \mathrm{Neu} 5 \mathrm{Ac}_{2}$ show mass errors greater than $2 \mathrm{ppm}$. Note the relative abundance measured for the $O$-linked glycoforms are no greater than $3 \%$ of the base peak during elution, yet excellent mass measurement accuracies result in high confidence in the assigned chemical structure for each of the glycoforms.

In addition to identifying the glycopeptides from the fetuin digest, protein sequence information was also acquired in one run. The full scan mass spectra acquired directly following the glycopeptide survey scan was used to direct data-dependent MS/MS experiments resulting in peptide sequencing information. Table 2 lists the enzymatic peptides identified using Bioworks Browser 3.2 which incorporates accurate mass of the precursor ions to increase confidence in peptide sequence assignment. In addition to the sequence and mass error, the cross-correlation (X-corr) scores reported from Bioworks are provided to evaluate goodness of fit between the experimental and theoretical MS/MS spectra. Note the X-corr values reported for precursor ions identified in the +1 charge state are sufficient for consideration. That is, a generally accepted X-corr value for peptides detected in the +1 charge state is 1.5 and the average $X$-corr for the eight identified singly charged peptides is 1.535 , indicating that a significant number of experimental b- and y-type fragment ions were matched to in silico fragmentation spectra [23]. In addition, the average mass error for the eight peptides was $0.42 \mathrm{ppm}$ increasing confidence in the assigned peptide sequence. Including the glycopeptides identified using accurate mass and tandem mass spectral analysis, a total of 325 of the reported 335 
Table 2. List of Identified bovine fetuin peptides from data dependent MS/MS scans. The cross-correlation value (X-corr) listed was that calculated from Bioworks 3.2. The accurate mass analysis was calculated from full scan mass spectral data acquired in the ICR cell. All cysteines were alkylated with iodoacetamide prior to digestion.

\begin{tabular}{|c|c|c|c|c|c|c|}
\hline Sequence & $\begin{array}{c}\text { Charge } \\
\text { state }\end{array}$ & Position & $\begin{array}{l}\text { Experimental } \\
\text { mass }\end{array}$ & $\begin{array}{c}\text { Theoretical } \\
\text { mass }\end{array}$ & $\begin{array}{l}\text { Mass } \\
\text { error } \\
\text { (ppm) }\end{array}$ & X-corr \\
\hline IPLDPVAGYK & 2 & $1-10$ & 536.80475 & 536.80550 & -1.40 & 2.084 \\
\hline EPA*CDDPDTEQAALAAVDYINK & 2 & $11-32$ & 1203.54346 & 1203.54191 & 1.29 & 4.965 \\
\hline HLPR & 1 & $33-36$ & 522.31476 & 522.31470 & 0.12 & 1.149 \\
\hline HTLNQIDSVK & 2 & $40-49$ & 577.81091 & 577.81091 & -1.63 & 3.263 \\
\hline VVVPR & 1 & $51-53$ & 557.3197 & 557.31945 & 0.45 & 1.297 \\
\hline QQTQHAVEGD*CDIHVLK & 3 & 89-102 & 659.98642 & 659.98596 & 0.70 & 3.683 \\
\hline QDGOFSVLFTK & 2 & $103-113$ & 635.32776 & 635.35733 & 0.70 & 3.001 \\
\hline${ }^{*}$ CDSSPDSAEDVRK & 2 & $114-125$ & 733.31494 & 733.31482 & 0.16 & 4.162 \\
\hline VVHAVEVALATFNAESNGSYKOKVEISR & 3 & $142-169$ & 1006.19794 & 1006.19673 & 1.20 & 7.021 \\
\hline AQFVPLPVSVSVEFAVAATD*CIAK & 2 & 170-193 & 1260.16614 & 1260.16435 & 1.42 & 5.826 \\
\hline EVVDPTK & 1 & $194-200$ & 787.41956 & 787.41960 & -0.05 & 1.998 \\
\hline${ }^{*}$ CNLLAEK & 1 & 201-207 & 847.43427 & 847.43421 & 0.07 & 2.219 \\
\hline QYGF*CK & 1 & $208-213$ & 802.35516 & 802.35524 & -0.10 & 1.288 \\
\hline GSVIQK & 1 & 214-219 & 631.37736 & 631.37720 & 0.25 & 1.617 \\
\hline ALGGEDVR & 2 & $220-227$ & 408.71402 & 408.71414 & -0.29 & 2.023 \\
\hline AHYDLR & 1 & 289-294 & 774.38947 & 774.38931 & 0.21 & 1.570 \\
\hline HTFSGVASVESSSGEAFHVGK & 3 & 295-315 & 707.33911 & 707.33963 & -0.74 & 6.383 \\
\hline TPIVGQPSIPGGVR & 2 & $316-330$ & 737.92145 & 737.92246 & -1.37 & 4.436 \\
\hline$L^{*} \mathrm{CPGR}$ & 1 & $331-335$ & 602.30817 & 602.30789 & 0.46 & 1.143 \\
\hline
\end{tabular}

amino acid residues were identified from the Bioworks search resulting in ca. $97 \%$ coverage. The ten residues not identified include the $\mathrm{T}_{4}(\mathrm{GYK} \mathrm{m} / \mathrm{z} 367)$ and $\mathrm{T}_{25}$ (VR $\mathrm{m} / \mathrm{z}$ 274) residues which fall below the mass range originally acquired in the ICR cell.

\section{Conclusions}

A sensitive and selective method for glycopeptide detection was presented using a hybrid linear ion trap/ FT-ICR mass spectrometer. Dissociation of glycopeptides in the source region and collection of the subsequent fragment ions proved to be very efficient using the LTQ-FT. Once collected in the linear ion trap, true tandem mass spectral analysis of the $\mathrm{m} / \mathrm{z} 204$ diagnostic sugar ion provides a sensitive and selective means for identification of glycopeptides despite coelution of unmodified peptides at greater ion intensities. In addition, the subsequent five scan events provided not only accurate mass analysis of intact molecular weights but oligosaccharide structural information in ca. $2 \mathrm{~s}$ per cycle. The combination of all three types of data acquisition was sufficient to fully characterize protein structure and posttranslational modifications at five different sites, including $\mathrm{N}$ - and $\mathrm{O}$-linked oligosaccharides, without having to enzymatically cleave the sugar moiety before mass spectral analysis. Including the glycopeptide identification and characterization, 97\% coverage was reported for the bovine fetuin enzymatic digest.

\section{Acknowledgments}

The authors gratefully acknowledge Craig Dufresne and Eric Stover for advice and insight regarding this work.

\section{References}

1. An, H. J.; Peavy, T. R.; Hedrick, J. L.; Lebrilla, C. B. Determination of N-Glycosylation Sites and Site Heterogeneity in Glycoproteins. Anal. Chem. 2003, 75, 5628-5637.

2. Jebanathirajah, J.; Steen, H.; Roepstorff, P. Using Optimized Collision Energies and High Resolution, High Accuracy Fragment Ion Selection to Improve Glycopeptide Detection by Precursor Ion Scanning. J. Am. Soc. Mass Spectrom. 2003, 14, 777-784.

3. Sandra, K.; Devreese, B.; Van Beeumen, J.; Stals, I.; Claeyssens, M. The Q-Trap Mass Spectrometer, A Novel Tool in the Study of Protein Glycosylation. J. Am. Soc. Mass Spectrom. 2004, 15, 413-423.

4. Wuhrer, M.; Koeleman, C. A. M.; Hokke, C. H.; Deelder, A. M. Protein Glycosylation Analyzed by Normal-Phase Nano-Liquid Chromatography-Mass Spectrometry of Glycopeptides. Anal. Chem. 2005, 77, 886894.

5. Morelle, W.; Michalski, J. C. The Mass Spectrometric Analysis of Glycoproteins and Their Glycan Structures. Current Anal. Chem.2005, 1, 29-57.

6. Medzihradszky, K. F.; Gillece-Castro, B. L.; Townsend, R. R.; Burlingame, A. L.; Hardy, M. R. Structural Elucidation of O-Linked Glycopeptides by High Energy Collision-Induced Dissociation. J. Am. Soc. Mass Spectrom. 1996, 7, 319-328.

7. Weiskopf, A. S.; Vouros, P.; Harvey, D. J. Characterization of Oligosaccharide Composition and Structure by Quadrupole Ion Trap Mass Spectrometry. Rapid Commun. Mass Spectrom. 1997, 11, 1493-1504.

8. Schulz, B. L.; Packer, N. H.; Karlsson, N. G. Small-Scale Analysis of O-Linked Oligosaccharides from Glycoproteins and Mucins Separated by Gel Electrophoresis. Anal. Chem. 2002, 74, 6088-6097.

9. Harvey, D. J. Identification of Protein-Bound Carbohydrates by Mass Spectrometry. Proteomics 2001, 1, 311-328.

10. Huddleston, M. J.; Bean, M. F.; Carr, S. A. Collisional Fragmentation of Glycopeptides by Electrospray Ionization LC/MS and LC/MS/MS: Methods for Selective Detection of Glycopeptides in Protein Digests. Anal. Chem. 1993, 65, 877-884.

11. Carr, S. A.; Huddleston, M. J.; Bean, M. F. Selective Identification and Differentiation of N- and O-Linked Oligosaccharides in Glycoproteins by Liquid Chromatography-Mass Spectrometry. Protein Sci. 1993, 2, 183-196.

12. Ritchie, M. A.; Gill, A. C.; Deery, M. J.; Lilley, K. Precursor Ion Scanning for Detection and Structural Characterization of Heterogeneous Glycopeptide Mixtures. J. Am. Soc. Mass Spectrom. 2002, 13, 1065-1077.

13. Carr, S. A.; Roberts, G. D. Carbohydrate Mapping by Mass Spectrometry: A Novel Method for Identifying Attachment Sites of Asn-linked Sugars in Glycoproteins. Anal. Biochem. 1986, 157, 396-406.

14. Jiang, H.; Desaire, H.; Butnev, V. Y.; Bousfield, G. R. Glycoprotein Profiling by Electrospray Mass Spectrometry. J. Am. Soc. Mass Spectrom. 2004, 15, 750-758.

15. Carr, S. A.; Huddleston, M. J.; Annan, R. S. Selective Detection and Sequencing of Phosphopeptides at the Low Femtomole Level by Mass Spectrometry. Anal. Biochem. 1996, 239, 180-192. 
16. Dziegielewska, K. M.; Brown, W. M.; Casey, S.-J.; Christie, D. L.; Foreman, R. C.; Hill, R. M.; Saunders, N. R. The Complete cDNA and Amino Acid Sequence of Bovine Fetuin. J. Biol. Chem. 1990, 265, 4354-4357.

17. Zhu, X.; Brorchers, C.; Bienstock, R. J.; Tomer, K. B. Mass Spectrometric Characterization of Glycosylation Pattern of HIV-gp120 Expressed in CHO Cells. Biochemistry 2000, 39, 11194-11204.

18. Juhasz, P.; Martin, S. A. The Utility of Nonspecific Proteases in the Characterization of Glycoproteins by High-Resolution Time-of-Flight Mass Spectrometry. Int. J. Mass Spectrom. 1997, 169/170, 217-230.

19. Schwartz, J. C.; Senko, M. W.; Syka, J. E. P. A Two-Dimensional Quadrupole Ion Trap Mass Spectrometer. J. Am. Soc. Mass Spectrom. 2002, 13, 659-669.

20. Staudacher, E.; Altmann, F.; Glossl, J.; Marz, L.; Schachter, H.; Kamerling, J. P.; Hard, K.; Vliegenthart, F. G.GDP-fucose: $\beta$-N-Acetylglucosamine (Fuc to Fuc $\alpha 1-6 \mathrm{GlcNAc}$ )-Asn peptide) 1-3-Fucosyltransferase Activity in Honeybee (Apis mellifica) Venom Glands.Eur. J. Biochem.1997451991751

21. Kannicht, C. In Posttranslational Modifications of Proteins; Humana Press: Totowa, New Jersey, 2002.

22. Syka, J. E. P.; Marto, J. A.; Bai, D. L.; Horning, S.; Senko, M. W.; Schwartz, J. C.; Ueberheide, B.; Garcia, B.; Busby, S.; Muratore, T.; Shabanowitz, J.; Hunt, D. F. Novel Linear Quadrupole Ion Trap/FT Mass Spectrometer: Performance Characterization and Use in the Com- parative Analysis of Histone H3 Posttranslational Modifications. J. Proteome Res. 2004, 2, 5-10.

23. Tabb, D.; McDonald, W. H.; Yates, J. R. I. DTASelect and Contrast: Tools for Assembling and Comparing Identification from Shotgun Proteomics. J. Proteome Res. 2002, 1, 21-26.

24. Cooper, C. A.; Gasteiger, E.; Packer, N. H. Glycomod-A Software Tool for Determining Glycosylation Composition from Mass Spectrometer Data. Proteomics 2001, 1, 340-349.

25. Cooper, C. A.; Gasteiger, E.; Packer, N. H. In Predicting Glycan Composition from Experimental Mass Using GlycoMod; Humana Press: Totowa, NJ, 2003.

26. Medzihradszky, K. F.; Maltby, D. A.; Hall, S. C.; Settineri, C. A.; Burlingame, A. L. Characterization of Protein N-Glycosylation by Reversed-Phase Microbore Liquid Chromatography/Electrospray Mass Spectrometry, Complementary Mobile Phases, and Sequential Exoglycosidase Digestion. J. Am. Soc. Mass Spectrom. 1994, 5, 350-358.

27. Sullivan, B.; Addona, T. A.; Carr, S. A. Selective Detection of Glycopeptides on Ion Trap Mass Spectrometers. Anal. Chem. 2004, 76, 3112-3118.

28. Zhang, S.; Chelius, D. Characterization of Protein Glycosylation Using Chip Based Infusion Nanoelectrospray Linear Ion Trap Tandem Mass Spectrometry. J. Biomol. Tech. 2004, 15, 120-133.

29. Huang, Y.; Mechref, Y.; Novotny, M. V. Microscale Nonreductive Release of O-Linked Glycans for Subsequent Analysis Through MALDI Mass Spectrometry and Capillary Electrophoresis. Anal. Chem. 2001, 73, 6063-6069. 